\title{
Dietary Practices and Influencing Factors of Winneba SHS Students
}

\author{
Linda Cobbah ${ }^{\mathrm{a}} \&$ Ebenezer Appah Bonney ${ }^{\mathrm{b}, *}$ \\ ${ }^{a}$ University of Education, Winneba, Ghana \\ ${ }^{b}$ Peki College of Education, Ghana
}

\begin{abstract}
The study examined the influence of dietary practices on the academic performance of boarding school adolescents. The sample consisted of 264 selected boarding school students from forms one, two and three, respectively. A multistage sampling procedure was adopted in the selection of respondents and structured questionnaire was the main instrument for data collection. The Cronbach's alpha reliability of the instrument was 0.82 . Data were quantitatively analysed using descriptive statistics and presented in the form of tables. The study revealed that consumption of unhealthy snack foods, skipping of meals especially breakfast and low intake of fruits and water were dietary practices which were influenced by several factors with hunger ranking highest. It was concluded that the students engage in poor dietary practices such as skipping of breakfast, and excessive snacking. Recommendations given included; educating the students on the importance of adopting positive dietary practices such as regular breakfast intake and moderate snacking in order to maintain general wellbeing, remain active in class and achieve higher test scores throughout their course period.
\end{abstract}

(C) 2021 Author(s). All rights reserved.

Keywords: Winneba SHS; dietary practices; academic performance.

\section{Introduction}

The development of a community or a nation is highly dependent on a host of factors of which nutrition is inclusive. Proper nutrition which culminates from a positive dietary practice is one of the key factors to developing and maintaining optimal health and longevity. According to Moody (2009), life expectancy worldwide has increased due to the technological advancement and improvement in medicare, hence reducing death rate from infectious diseases drastically. However, death rate from degenerative or diet-related diseases seems to be escalating at an alarming rate especially during the adulthood stage of human development.

One will not be far from right to argue that the diet-related diseases prevalent in adult years could be ameliorated by dietary modifications in the younger years. According to WHO (2020), a convenient way to define adolescence is by considering age although it is only one among many criteria that describes this period of human development. In view of this, WHO (2000) described adolescence as the period of life from ages 10-19 years.

Admittedly, adolescence is known to be one of the most rapid changing phases of human development and these changes may have diverse health implications the adolescents may also extend to cover other phases in the life-course.

Since this is the stage at which individuals begin to make dietary decisions, it must be a matter of prime concern to ensure that adolescents of today adopt the right dietary practices coupled with other healthy practices. These would ensure that they enjoy good health and longevity in their adult years and become productive citizens for national development.

\footnotetext{
* Corresponding author.

E-mail address: bonney2007@yahoo.co.uk (Ebenezer Appah Bonney)
} 
Befort et al. (2006) reported that adolescents form dietary habits affecting health status that will persist into adulthood. Healthy dietary behaviour is therefore essential for proper growth and development of every individual as far as adolescence is concerned. In the opinion of Waugh and Grant (2010), adolescents often obtain half to two-thirds of all their calories and major nutrients from snacks which are mostly on pastries, cakes, candies, ice cream and carbonated fizzy drinks. The fact of the matter is that snacks and fast food restaurants that serve and sell these foods are not the major problem but the poor food choices of adolescents in terms of type, quantity and frequency (Owusu, 2007). This situation is not uncommon among Ghanaian Senior High School students.

In this wise, one of the most important ways to enjoy a healthy lifestyle and longevity is to adopt proper dietary practices which is described by Amoako-Kwakye (2010) as the typical observable behaviours of specific groups of persons in relation to food intake. She further explained that it cuts across food choices, eating times, number of meals, size of portions, method of food preparation and service among others.

An individual who constantly takes in healthy diet or nutritionally balanced meals is sure to protected from all forms malnutrition, and non-communicable diseases (NCDs) such as heart disease, stroke, diabetes and cancer (WHO 2018).

The development or adoption of a particular dietary practice; be it healthy or otherwise can be affected by lifestyle situations and may be influenced by several factors such as family, peers, and the media through patronage and advertisement. Notwithstanding these, the dietary practices of most adolescents have not contributed much to enjoying healthy life in later years and this is an issue worth considering. It is against this back drop that the study sought to examine the dietary practices of boarding students in Winneba SHS and identify factors that influence the dietary practices of the students.

\section{Statement of the problem}

Research has proven that most adolescents in boarding schools adopt dietary practices such as excessive consumption of convenience foods, snacking, and skipping of meals among others. These practices are usually influenced by a wide range of factors. Hence, one is left wondering whether boarding students in Winneba SHS have similar or different dietary practices and possible factors that influence the development of those practices. Furthermore, there has not been any research on the dietary practices and influencing factors of Winneba SHS students in the Effutu Municipality since its establishment in the year 1949. It is against this backdrop that the researcher considered the study worthwhile.

\section{Objectives of the study}

Specifically, this study sought to:

a) explore the dietary practices of boarding students in Winneba SHS as regards choice, preference, time, frequency and pattern of eating meals.

b) identify factors that influence the dietary practices of the students.

\section{Research questions}

The following research questions guided this study:

a) What dietary practices are exhibited by Winneba SHS boarding students?

b) What factors influence dietary practices of these students?

\section{Literature Review}

Understanding the dietary behaviour one exhibits and the factors that are likely to influence such practices are strengthened by a number of learning theories. This study is underpinned by the need theory of Maslow and further leans on its relationship to Vygotskys' theory of cultural needs.

According to Maslow (1943) human needs comes in different levels or hierarchical order ranging from basic or simple to complex. He presented the cluster of needs in order of increasing importance as follows: physiological or physical, safety, social, esteem and self-actualisation needs. Maslow (1943) described the body's physiological or physical need 
for food, especially in terms of maintaining homeostasis or balance of water, salt, macronutrients, vitamins, minerals and temperature within the bloodstream. He further stated emphatically that:

"Undoubtedly these physiological needs are the most pre-potent of all needs...If all the needs are unsatisfied, and the organism is then dominated by the physiological needs, all other needs may become simply nonexistent or be pushed into the background...for consciousness is almost completely pre-empted by hunger. For the chronically and extremely hungry man, life itself tends to be defined in terms of eating and anything else will be defined as unimportant" (pp. 373-374).

In contrast to the authoritative role of food, however, the need for achievement is among the least compelling needs. According to Maslow (1943), all humans irrespective of the society they find themselves in have the need or desire for self-esteem that is deeply based upon real competency or ability, accomplishment, love and respect from others in a particular society. It is vital to consider Maslow's statement that when an individual's needs on one level, usually lower one, are satisfied, other needs at higher levels comes to light and dominates the individual's thoughts and behaviour. Hence, Maslow's hierarchy indicates that, the need or desire for achievement which is a higher-level need will not occupy a person's thoughts and behaviours until needs on the lower levels have been satisfied first. For this reason, one cannot achieve the intellectual processes and behaviours related to the intricate levels on the hierarchy. Magnificent academic performance is usually not expected from students who are suffering from the deprivation of their basic needs such as such as food in the form of hunger. Hence, from the very foundation, individuals who have nutritional deficiencies due to their basic nutritional needs not being satisfied over a period will have difficulty achieving their higher levels needs. Despite the fact that Maslow's hierarchy presents an illustrative relationship between food and reasons for eating, it also brings up three relevant questions that require thoughtful considerations:

(1) To achieve an individual's basic physiological needs, what foods must people consumed?

(2) Is there the possibility that certain diets better satisfy a person's basic needs than others?

(3) Can people circumvent their basic needs in order to achieve a superior achievement on subsequent hierarchal levels?

Maslow's hierarchy of needs provided a framework for understanding a fundamental link between food and factors that influenced food intake. However, Asare and Kwafoa (2011) argued that some people may either intentionally deny themselves of satisfying a lower level need in order to achieve a higher one or be unable to satisfy their basic needs adequately but would want to achieve higher level ones while another set of people may realize their highest potential (self-actualisation) but may not be able to satisfy their basic needs. These notwithstanding, AmoakoKwakye, 2010 contend that food as a basic and lower level need must be eaten primarily for biological reasons, that is, for survival before other reasons may be considered. Irrespective of the level of need driving an individual, food is inevitable in the equation of health and survival. However, the quality, quantity and kind of food selected and eaten by an individual would be influenced by one or more of the factors such as socio-cultural, economic, physiological and psychological.

In view of this, Vygotsky added another layer of understanding with his apt consideration of the socio-cultural dynamics. Vygotsky and the socio-culturalists explained these phenomena by asserting that a person's context shapes his or her behaviour, by influencing eating habits and determining priorities in living. They argued that

"a culture defines what knowledge and skills children need to acquire" and that values and processes "differ among different races, social classes, dual-career versus one-career families, rural versus urban communities, single-parent versus two-parent families, and so on" (Vygotsky, 1978, pp. 47, 50).

Maslow and Vygotsky provide a context for two main approaches from their perspectives. These are physiological and cultural approaches to how food intake or dietary practices (habits) are formed. Nutrition, health and diet in general appear to be affected by an array of socio-cultural factors among several others. There are distinct differences in nutrient consumption that appear both internationally and among population subcultures because of food availability, preference, and social norms. Undoubtedly, these dietary trends are especially prominent in comparisons of socioeconomic status and ethnicity which may have a direct influence on dietary practices among individuals from cultures and subcultures worldwide. 


\section{Conceptual framework}

The interrelationships of past theoretical and empirical efforts enabled the researcher to propose a conceptual model on the dietary practices of second cycle students and the possible influencing factors. The conceptual framework for the topic under study is presented in Fig. 1.

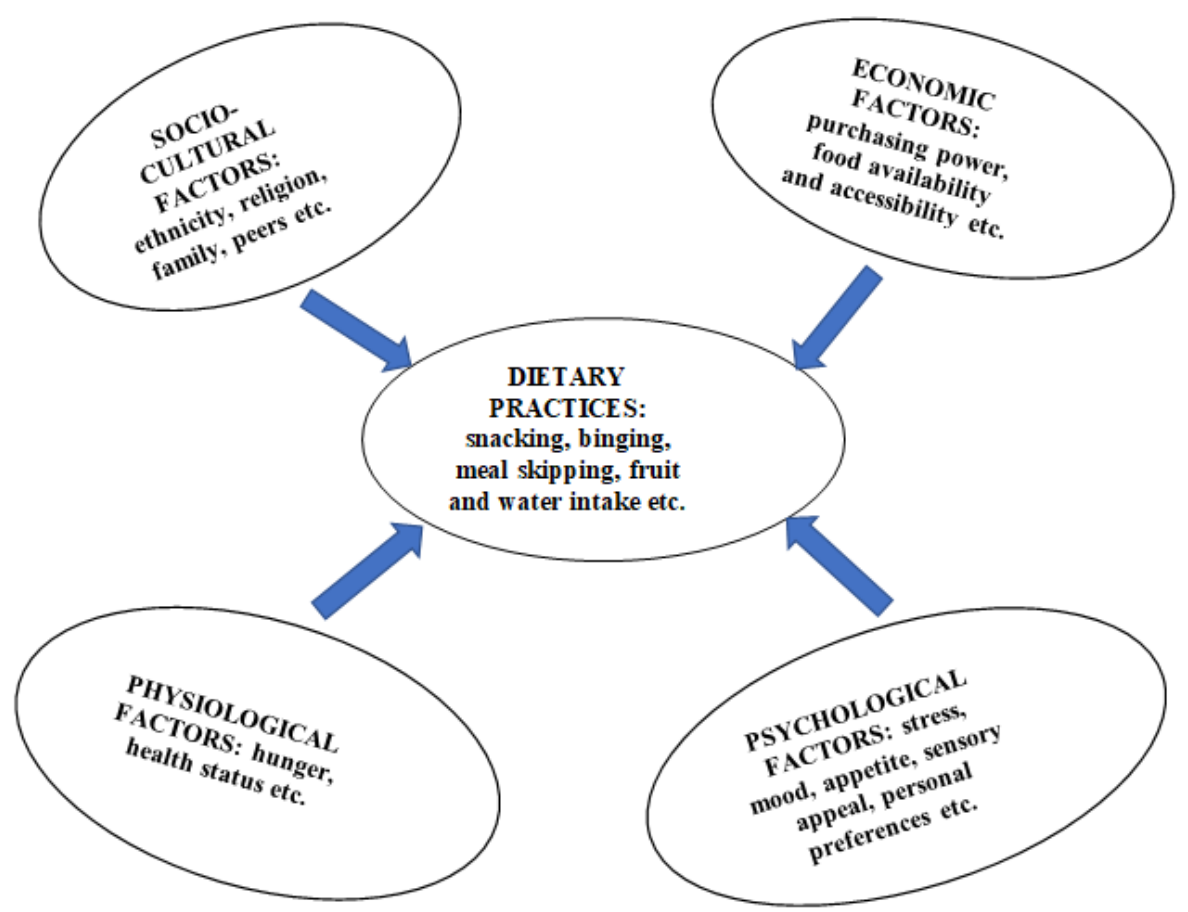

Fig. 1. Conceptual framework on dietary practice and academic performance

Dietary practice explains and indicates the reason and manner in which people eat, the kinds of food the consume, and with whom they eat, as well as the ways people obtain, store, use, and discard food. It refers to food choices, eating times, number of meals eaten, size of portions per meal, method of food preparation and service among others (Amoako-Kwakye, 2010). Snacking habits, consumption of convenience, sugary, salty or fatty foods, meal skipping, binging, and compulsive eating are some examples of dietary practices that individuals adopt of which adolescents are no exception (Bediako, 2011).

Numerous factors influence dietary practices of students. These include, but are not limited to cultural factors such as ethnicity, religion, superstition and food taboos, geographical location and physiological needs for nourishment of the body. Hunger, appetite, aversion, sensory appeal, personal preferences as well as food availability, food accessibility, peers, family, media, and technological influences, as well as financial status and acculturation are also identified as factors that influence dietary practices (Barasi, 1997). According to Amoako-Kwakye (2010) people eat food and in choosing what food to eat, four major factors either collectively or distinctively influence the dietary practice that is adopted at any point in time. These factors are socio-cultural, economic, physiological and psychological in nature.

Socio-culturally, it can be argued that most people feel comfortable to eat meals that they are familiar with especially family meals, even when they are away from home. Parents usually feed their children with what they were fed on by their own parents hence the tradition continues throughout generations. People belonging to the same ethnic group may have the same culture with special regards to the selection, preparation and services of meals.

Religious beliefs and rituals may also influence one's choice of diet as certain foods may be prohibited to be taken by members. People of similar age group or social status may influence themselves on certain decisions and food intake cannot be exempted. The individuals an adolescent usually associates with and shares meals with can influence their 
dietary practice to a great extent. Meals served at school and time of eating can also alter the dietary practice of the adolescent.

The choice of food an individual makes is basically determined by that person's physiological needs. For this reason, an individual requires some amount of energy coupled with other nutrients for ensuring survival. hunger and satiety are two biological phenomena that move people to eat. Hunger is an uncomfortable feeling one gets as a result of not eating food over a period and presents the need to satisfy appetite for food while satiety on the other hand is the state of fullness after eating or the state in which one does not feel hungry from the time one ate to the time one eats the next meal. The body responds to the feelings of hunger and satiety through the central nervous system which is involved in controlling the balance between hunger, appetite stimulation and food intake (Amoako-Kwakye, 2010). One other physiological factor that influence dietary practice is health. Certain health conditions such as diabetes, stomach ulcer, constipation, hypertension etc. are diet related and can therefore be best managed by dietary modifications which when practiced over a period could become a dietary practice for that particular individual. Hunger makes a person eat just anything that is edible, available and accessible (Wardlaw \& Smith, 2009).

Economically, a person's income level or economic status determines the purchasing power which is the ability to afford a desired good or service including the type, quality and quantity of food to be consumed (Adigbo, \& Maddah, 2011). Undoubtedly, the basic determining factor of food choice is affordability or the cost of food. An individual's income level and socio-economic status basically determines whether cost is extortionate. Arguably, the probability of individuals whose income level is low to consume unbalanced diets and in particular have low intakes of high-quality protein foods, fruits and vegetables is high. Nevertheless, having access to more money or having a level higher level of income does not guarantee that the individual will certainly consume a balanced or better-quality diet. However, one will have a larger quantity and wider range of foods at his or her disposal to select from.

Psychological factors that influence dietary practice formation as identified by Amoako-Kwakye (2010) include appetite, sensory appeal, food aversion and personal preferences among others. One's unpleasant experience regarding a particular food in the past has the capability to alter the visual, textual, chemical (taste, flavour) and other real properties of the food make the individual reject it and vice versa. The sense of belongingness that food brings as well as the establishment of certain status influence dietary habit. Modern life and its complexities present people with a lot of stress that require behaviour modification which consequently have a bearing on food choices and general wellbeing. The impact of stress on the choice of food cannot be underscored regardless of the type of stress one is experiencing. The individual, the stressor and the circumstances contributing to the stress are some underlying factors that highly determine the impact of stress on food intake. General, when people are experiencing stress their appetite and frequency of eating as well as the portions of food they eat at a time usually change dramatically and this differ from individual to individual. While some experience high appetite for food and therefore eat more, others rather experience poor appetite for food and therefore eat abnormally less than they would under normal circumstances. The proposed systems for stress induced changes in food intake and dietary practice are motivational differences (reduced concern about weight control), physiological (reduced appetite caused by the processes associated with stress) and practical changes in eating opportunities, food availability and meal preparation. Mood is another psychological factor worth mentioning. Research has it that food influences mood and that mood in turn has a strong influence over choice of food. Interestingly, it appears that the influence of food on mood is related in part to attitudes towards particular foods (Wardlaw \& Smith, 2009).

In view of the above discourse, it can be seen that one's choice of food and dietary practice in general is either directly propelled by a particular level of need (physiological safety, social, esteem, and self-actualization) or the sociocultural beliefs and values prevalent within the individual's society. Hence, the formation of a particular dietary practice does not erupt out of the blue but backed by either of the theories earlier discussed.

\section{Methods}

The study adopted the descriptive survey design since it permitted the researcher to gather data from a sample that is representative of the population and described situations as they existed (Fraenkel \& Wallen, 2000). The study was conducted at Winneba S.H.S. which is the sole public S.H.S. in the Effutu municipality with accessible population of 1600 boarding students. These students come from diverse backgrounds but with their ages ranging from 15 to 19 
years representing a homogeneous group of adolescents that share similar characteristics as such: experiencing of growth spurt, mood swings, and self-awareness as well as being in the boarding house and having school-based feeding, just like students from other S.H.S. nationwide.

A sample of 264 representing $16.5 \%$ of population was purposively drawn from the 1,600 students in the boarding house. The sample was then stratified by gender and by class after which simple random sampling (fish bowl) method was employed to get sample desired.

A structured questionnaire was developed and used to gather data which provided responses to the research questions raised.

\subsection{Validity of the instrument}

Awanta and Asiedu-Addo (2008) and Alhassan (2006) described validity of a research instrument simply as being concerned with how well it measures the concept(s) it is intended to measure. As regards this study, content and face validity were considered. Content-related evidence helps to determine if the instrument covers an appropriate or adequate sample of the domain it is supposed to represent or reflect (Fraenkel \& Wallen, 2000). In order to ensure that the items in the instrument used were valid; two senior lecturers from the Home Economics Department and two others from the Psychology and Education Department in the University of Education, Winneba, subjected the instrument to scrutiny by proof reading in order to make all the necessary corrections before they were administered for subsequent analysis.

\subsection{Reliability of instruments}

From the perspectives of Eshun and Effrim (2007), reliability also concerns itself with the consistency of results of the use of a particular instrument. That is the tendency to obtain the same results if the measure was to be repeated by using the same subjects under the same conditions. The instrument was pilot tested on 30 first, second and third year students from Apam SHS, a public school in the Gomoa West District in the Central Region. This is a mixed gender school with both day and boarding students who possess similar characteristics as the students in Winneba SHS and therefore helped in ascertaining the reliability of the instrument. Data collected from the pilot test was then used to analyse the reliability of the instrument to determine the internal consistency of responses to the test items. The result from the pilot test indicated the questionnaire was reliable. This was evidenced by reliability measure of 0.82 , using the Cronbach's Alpha reliability coefficient.

\section{Result and Discussion}

\section{Research Question 1:}

\section{What are the dietary practices of boarding students in Winneba SHS?}

Table 1 shows the responses of students on dietary practices.

Table 1. Number of times the boarding school students eat main meals in a day

\begin{tabular}{lcc}
\hline \multicolumn{1}{c}{ Number of times } & Freq. & \% \\
\hline Once & 0 & 0 \\
Twice & 78 & 30 \\
Thrice & 186 & 70 \\
\hline Total & 264 & 100 \\
\hline
\end{tabular}

Thirty per cent (30\%) of the students ate twice in a day, whiles $70 \%$ of them ate thrice per day but none ate once in a day as indicated in Table 1.

The students were also asked whether they sometimes skip any of the three main meals of the day and their responses indicated that, $53 \%$ (Yes) skipped meals while the remaining $47 \%$ (No) did not. 
The students who indicated they skipped some of their meals were asked further to indicate which meals they skipped. Table 2 presents the result on the type of meal those students skipped.

Table 2. Type of meals skipped by the students

\begin{tabular}{lcl}
\hline Type of meal & Freq. & \% \\
\hline Breakfast & 76 & 54 \\
Lunch & 46 & 33 \\
Supper & 18 & 13 \\
\hline Total & 140 & 100 \\
\hline
\end{tabular}

$\mathrm{N}=140<264$ due to 164 students indicating not skipping meals.

The results in Table 2 show that out of the students who skipped meals, as many as $54 \%$ of the students skipped breakfast, $33 \%$ sometimes skipped lunch, and $13 \%$ of them sometimes skipped supper.

The students were asked to indicate whether they sometimes eat outside the school dining hall. The results revealed that $68 \%$ of the students sometimes ate outside the school dining, whereas $32 \%$ of them did not.

The students who earlier indicated they ate outside the school dining hall were further asked to indicate the kinds of meals they preferred eating and the results are presented in Table 3.

Table 3. Preferred meals eaten outside the school dining hall by the students

\begin{tabular}{lcc}
\hline Preferred meal & Freq. & $\%$ \\
\hline Plain rice/waakye with stew & 72 & 40 \\
Banku/kenkey with soup/stew & 26 & 15 \\
Red-red and gari & 22 & 12 \\
Boiled yam/plantain (ampesi) with stew & 21 & 12 \\
Hausa koko with bread/koose & 20 & 11 \\
Others & 18 & 10 \\
\hline Total & 179 & 100 \\
\hline
\end{tabular}

$\mathrm{N}=179<264$ due to 85 students indicating not eating outside the school dining hall.

Table 3 presents the responses on foods which students normally ate outside the school dining hall. Plain rice/ waakye with stew were the preferred meal for $40 \%$ of the students, while banku/kenkey with soup/stew was preferred by $15 \%$ of the students.

Twelve per cent (12\%) each preferred red-red and gari and boiled yam/plantain (ampesi) with stew, while $11 \%$ preferred Hausa koko with bread/koose and $10 \%$ preferred other meals especially indomie instant noodles. The students' responses on preferred meal eaten for breakfast are presented in Table 4.

Table 4. The students' preferred meals for breakfast

\begin{tabular}{lll}
\hline Preferred breakfast meals & Freq. & \% \\
\hline Hausa koko (porridge) with bread/koose/puff loaf. & 80 & 36 \\
Rice porridge, tom brown, rashes with bread & 71 & 27 \\
Beverage like tea/milo with bread & 57 & 22 \\
Others & 55 & 15 \\
\hline Total & 264 & 100 \\
\hline
\end{tabular}

The data in Table 4 gives information on what students preferred to eat for breakfast. Thirty-six per cent (36\%) of the students preferred Hausa koko (porridge) with bread/kooselbeff, $27 \%$ preferred rice porridge, tom brown or rashes with bread while $22 \%$ preferred beverage like tea or milo with bread. Fifteen per cent (15\%) of the students preferred other foods such as gari with shito, banku/kenkey with fish, yam and stew at breakfast. 
Water intake is one of the essential aspects of diet, thus the researcher inquired of the students to indicate the volume of water they consumed averagely in a day. Their responses are presented in Table 5.

Table 5. The Students' Response on Water Intake

\begin{tabular}{lcc}
\hline Volume of water & Freq. & \% \\
\hline 3 sachets or less & 168 & 64 \\
4 - 6 sachets & 86 & 32 \\
7 sachets or more & 10 & 4 \\
Total & 264 & 100 \\
\hline
\end{tabular}

The information provided in Table 5 shows that, a larger portion (64\%) of the students' daily water intake was 3 sachets (1.5 litres) averagely, 32\% had 4 to 6 sachets (2-3 litres) of water where as $4 \%$ had an average daily water consumption of 7 (3.5 litres) and above.

Regarding fruits intake as a dietary practice, the students were required to indicate how often they ate fruits and their responses are presented in Table 6.

Table 6. The students' responses on their fruits intake

\begin{tabular}{lcl}
\hline Intake of fruits & Freq. & \% \\
\hline Seldom & 156 & 59 \\
Weekly & 56 & 21 \\
Daily & 52 & 20 \\
\hline Total & 264 & 100 \\
\hline
\end{tabular}

The information from Table 6 shows that, 59\% seldom ate fruits, $21 \%$ ate fruits weekly and the remaining $20 \%$ took in fruits on a daily basis.

Furthermore, respondents were asked to indicate whether or not they took in small and dainty foods (snacks) so that the researcher could ascertain their snack intake and their responses revealed that, as many as $97 \%$ of the students ate snacks while 3\% did not. Those students who indicated they ate between main meals (snacks) provided information on how often they consumed it. Table 7 provides the results.

Table 7. The students' response on the rate of snack intake

\begin{tabular}{lcl}
\hline Rate of consumption & Freq. & \% \\
\hline Very often & 139 & 54 \\
Often & 86 & 34 \\
Not often & 30 & 12 \\
\hline Total & 255 & 100 \\
\hline
\end{tabular}

$\mathrm{N}=255<264$ due to 9 students indicating not taking in snacks

The students who ate snacks constituted 97\% (255). The data in Table 7 indicate the rate at which those students ate snacks. The result shows that $54 \%$ of the students ate snacks very often, $34 \%$ often ate snacks, and $12 \%$ of them rarely ate snacks. This result shows that majority (88\%) of the students frequently consumed snack.

In furtherance to knowing the rate at which students snacked, respondents were asked to indicate the periods within the day that they consumed snacks and their responses are presented in Table 8.

Table 8 shows that $6 \%$ of the students ate snacks between the time of breakfast and lunch, $29 \%$ consumed it between the lunch and supper periods, $13 \%$ of them ate snacks between supper and bed time whereas $52 \%$ ate snacks at any time they deemed fit. The students who responded positively to the intake of snacks were further asked to indicate the foods they preferred to eat between meals. Table 9 presents the results. 
Table 8. The students' response on periods of snack intake

\begin{tabular}{lcc}
\hline Period of consumption & Freq. & $\%$ \\
\hline Between breakfast and lunch & 14 & 6 \\
Between lunch and supper & 74 & 29 \\
Between supper and bedtime & 34 & 13 \\
Other & 133 & 52 \\
Total & 255 & 100 \\
\hline
\end{tabular}

$\mathrm{N}=255<264$ due to 9 students indicating not taking in snacks

Table 9. The students preferred snack foods

\begin{tabular}{lcc}
\hline Preferred snack foods & Freq. & \% \\
\hline Pastries/biscuits/puff-loaf and drinks & 128 & 50 \\
Fried yam/sweet potatoes/ spring rolls & 69 & 27 \\
Roasted corn and groundnut & 32 & 13 \\
Cassava balls (agblikaklo) & 16 & 6 \\
Fruits & 10 & 4 \\
\hline Total & 255 & 100 \\
\hline
\end{tabular}

$\mathrm{N}=255<264$ due to 9 students indicating not taking in snacks.

According to Table 9 half (50\%) of the students preferred pastries, biscuits, puffloaf and drinks for snack, $27 \%$ preferred fried yam, sweet potatoes or spring rolls, while $13 \%$ liked roasted corn and groundnut, $6 \%$ preferred cassava balls (agblikaklo) and 4\% indicated fruits as their favourite snack. The results that were gathered indicated that $70 \%$ of the students ate main meals thrice in a day, while $30 \%$ ate twice in a day with none eating once in a day. This characteristic of dietary practices of students can be described as positive since all 264 students ate twice or thrice daily. This is justified by Wardlaw and Smith (2009) who concluded that eating at least more than once a day replenishes used nutrients in the body and puts the body in a good state for growth and development provided the meals are balanced in nutrients.

Slightly more than half of the students skipped meals. It was indicated by $53 \%$ of the students that they sometimes skipped meals, while $47 \%$ answered in the opposite. Skipping meals as a dietary practice has been found as one common characteristic of adolescents. This conforms to Poulain (2002) who found that among 4500 college students in Ottawa, skipping meals was a common dietary practise of $67 \%$ of the total population. This shows that skipping meals is very common among adolescents. Similarly, Dolar (2009) concluded from his research that $70 \%$ of adolescents skip at least one of the three main meals of the day. This dietary practice is also common among adolescents of Winneba SHS. Breakfast was found to be one of the meals skipped by the students. Out of 140 students who indicated they skipped any of the daily meals, $76 \%$ of the students usually skipped breakfast, $46 \%$ skipped lunch while 18\% sometimes skipped supper. Breakfast has been found to be the type of daily meal that is skipped by most adolescents. In a study of eating habits of students in selected SHS in Cape Coast, Mensah (2006) found that 55\% of students skipped breakfast; however, this was common among females rather than males.

Among the boarding students, another dietary practice found was eating outside the dining hall. The school dining menu is planned by nutritional experts taking into consideration students' nutritional needs. It is an undisputed fact that meals prepared outside the school and meals prepared in the schools kitchen cannot be the same. It was affirmed by $68 \%$ of the students that they ate outside the school dining hall whereas $32 \%$ did not. Eating outside the schools' dining hall is a common practice among SHS students. In Mensah's (2006) study, $48 \%$ of students preferred outside meals to meals prepared in the schools kitchen. Mensah concluded that majority of boarding students ate from the schools dining hall. However, there was always the case where a section of students preferred to eat food outside the school's dining hall.

Irregular fruit intake was yet another dietary practice that became evident from the result of the responses of students. A question was asked to ascertain the regularity of fruit intake by the students and the results show that, majority constituting $78 \%$ did not consume fruits on daily basis while the remaining $22 \%$ responded in the affirmative. In the 
United States, the USDA identified that there were poor fruit intake habits among adolescent students. This situation called for an intervention; fresh fruits and vegetables programme was introduced to all at-risk schools in the fifty states to help improve quality of students' diet (Briggs, Mueller \& Fleishhacker, 2010; Frongillo, Jyoti \& Jones, 2006).

Students' snacking habits were assessed and the results showed $97 \%$ affirmed that they ate snacks while $3 \%$ answered in the opposite. This indicates that students preferred snacks. The pattern of how they ate snacks showed that while $60 \%$ ate snacks very often, $29.7 \%$ ate snacks often. However, $10.3 \%$ indicated that they did not eat snacks often. The results from Table 4.5 show that $74.8 \%$ indicated they ate snacks in the mornings, $25.5 \%$ indicated they ate snacks in the afternoons, $11.7 \%$ ate snacks in the evenings and $57.9 \%$ ate snacks in between meals. This implies, students often ate snacks anytime within the day. The result conforms to findings from a survey conducted by Mensah (2006). In the survey, snacking was reported by $90 \%$ of the adolescents. Taking snacks in itself is not bad as it helps compliment the major meals (breakfast, lunch and supper) of the day in nutrients (Tull, 1996). However, wisely chosen snacks are most important irrespective of the high amount of energy needed by adolescents. USDA Nationwide Food Consumption Survey reported that, snacks constituted as much as a third of adolescents' daily energy intake, and quite a substantial quantities of micronutrients (Philips, 2009).

Outside Ghana, Dwyer, Blizzard and Dean (2001) found that $87 \%$ to $88 \%$ of American adolescents between the ages of 12 and 18 years consume at least one snack on a daily basis. In European countries, Anderson, Macintyre and West (1994) found that Scottish adolescents aged 15 years consumed as much as 2-3 snacks per day. In Asian countries, adolescents consume at least one snack per day constituted $86 \%, 71 \%$, and $10 \%$ of Filipino, Russian and Chinese respectively (Adair \& Popkin, 2005).

Based on students' water intake, findings gathered indicated that a larger portion (64\%) of the students' daily water intake was three sachets averagely, $32 \%$ had four to six sachets of water whereas $4 \%$ had an average daily water consumption of seven and above. The results show that although not very bad, there is still some room for improvement in the students' water intake. This is because their intake of water defer slightly from recommended daily water to be consumed by the human body. It takes 8 to 10 glasses of water which is approximately 6 to 7 sachets to replenish the volume lost by the body through perspiration and other body processes. The WHO (2006) recommends a minimum 8 glasses of water to be drunk daily. Similarly, Wardlaw and Smith (2009) indicate that more than 8 glasses of water should be drunk daily to keep the body well hydrated. They add that this practice has much health advantage than is imagined. Especially in the tropical part of the world where the heat from the sun gets high, it becomes very important that water consumption is taken seriously. Wardlaw and Smith (2009) emphasised their interest in water intake because water is said to constitute greater part $(65 \%-70 \%)$ of the human body; it forms the greater portion of blood and the entire body weight. It is therefore an essential nutrient if it is to be judged by how long one can live without it.

Commenting on intake of water among adolescents, Wardlaw and Smith (2009) affirms that adolescents drink water to only quench their thirst with little or no concentration on meeting recommended water intake by dieticians and nutritionists. This dietary practice by adolescents fits only into Maslow's theory of needs where adolescents drink water to quench their thirst but not to satisfy their dietary needs.

Adigbo and Maddah (2011) maintain that averagely, an individual is capable of staying alive for only eight to ten days without drinking water on the contrary a person can only die of hunger after several weeks or even months without food consumption. This illustrates that water is indispensable element for human survival. They contend that a person's need for water depends on one's level of physical activity and state of health.

For instance, an athlete or manual worker's need for water is higher than that of a sedentary person since the need for water is determined by how much water is lost by the body through urine, perspiration and faeces. Adolescents have high energy levels and are naturally active. They constantly engaged in abstract thinking, deductive reasoning and problem solving while learning in school and exercising their brains (Brown, 2012). Wardlaw and Smith (2009) described that during adolescence, there is an increased need for more water in the human body to maintain homeostasis and to replenish that which is lost in activities such as jogging, running, talking, writing, reasoning and abstract thinking engaged in by the adolescents. Wardlaw and Smith (2009) mentioned that water is said to serve as the vehicle for transporting oxygen, nutrients and other substances throughout the body. It helps in the removal of 
waste product like sweat faeces, and urine. It helps in maintaining the natural balance between dissolved salts and water inside and outside body cells. It also aids digestion of food and the absorption of nutrients; makes swallowing possible by lubricating the gut and regulates the human body temperature, quenches thirst and refreshes the body. These processes help in the normal functioning of the minds of students which has a high possibility of improving their academic performance.

\section{Research question 2:}

What factors influence the dietary practices of the students?

The data for this research objective were obtained from responses to questionnaire. Information was sought on factors influencing dietary practices of the students. Students were given a number of possible factors that are likely to influence their dietary practices for them to indicate their agreement or disagreement on each of the following options: health condition, peer influence, religion and parental/family influence, school dining menu, food availability, hunger and purchasing power. Table 10 presents the results of the students' responses.

Table 10. Factors influencing dietary practices of the students

\begin{tabular}{lccccl}
\hline Factors & SA & A & D & SD & TAR in rank \\
\hline Hunger & $84(32)$ & $165(63)$ & $0(1)$ & $11(4)$ & 1st (95) \\
Availability of food & $220(83)$ & $28(11)$ & $8(3)$ & $8(3)$ & 2nd (94) \\
Health condition & $134(51)$ & $82(31)$ & $48(18)$ & $0(0)$ & 3rd (82) \\
Family influence & $124(47)$ & $86(33)$ & $50(19)$ & $4(1)$ & 4th (80) \\
School dining menu & $106(40)$ & $82(31)$ & $46(17)$ & $32(12)$ & 5th (71) \\
Purchasing power & $98(37)$ & $70(27)$ & $48(17)$ & $51(19)$ & 6th (64) \\
Peer Influence & $105(40)$ & $63(24)$ & $42(16)$ & $54(20)$ & 6th (64) \\
Religion & $60(23)$ & $98(37)$ & $64(24)$ & $42(16)$ & 8th $(60)$ \\
\hline \multicolumn{7}{r}{} \\
\hline
\end{tabular}

Key: SA - Strongly Agree; A - Agree; D - Disagree; SD - Strongly Disagree;

TAR - Total Agreed Responses Note: The numbers in parentheses are the percentages.

Table 10 presents data on the factors which influence dietary practices of the students. Ninety-five per cent (95\%) of the students agreed that hunger influenced their dietary practices, whereas $5 \%$ objected. Similarly, $94 \%$ of the students indicated that purchasing power was a factor which contributed to their dietary practices. However, $6 \%$ of them held an opposing view. With regards to health as an influencing factor of dietary practices, $82 \%$ of the students admitted and $18 \%$ of them disagreed. Similarly $80 \%$ confirmed that family values influenced their dietary practices while $20 \%$ did not. In addition, $71 \%$ of the students consented while $29 \%$ of them disagreed that the school dining menu contributed to their dietary practices. About two-thirds of the students (64\%) agreed, whereas $36 \%$ of them disagreed that the availability of food was a factor which influenced their dietary practices. Moreover, $64 \%$ of the students further agreed while $36 \%$ disagreed that their peers influenced their dietary practices. Lastly, $60 \%$ of the students affirmed while $40 \%$ disagreed that religion was a factor that influenced their dietary practices. The results indicated that out of the several possible factors that influence the dietary practices, hunger was the strongest factor that influenced students' dietary practices. It was agreed by $95 \%$ of students that hunger influenced their food choices. This implies that as part of the adolescents physiological and physical development, they are likely to experience rampant hunger pangs that heighten their appetite for meals without thinking about their nutritional state. It is therefore not surprising that adolescents take in snacks constantly and will grab 'anything' that is edible and have some form of satiety value. This result also stands to prove Maslow's theory of needs to be most true. The results support Maslow's theory of needs which considers physiological need as the basic and first need of humans before anything is else is considered (Maslow, 1943). The results similarly connect with Wardlaw and Smith (2009) who established that the primary reason for eating is to replenish lost nutrients in the body. They explained that at the point of hunger the human will require food of any form to satisfy hunger and ensure the feeling of wellness. Mensah (2002) established that hunger is the most pertinent reason why we eat. Mensah identified among 500 SHS students that they were influenced to eat because of hunger. The results show that adolescents are influenced to eat when 
hunger sets in. This implies that adolescents to some extent may be influenced to eat any available food because they are hungry.

From the results in 10, it was indicated by $94 \%$ of the students that they were influenced to eat based on food that is available. This factor was ranked second among the other factors that influence dietary practices of students. Thembe (2009) stated that it is not very common for people to be selective with food at the peak of hunger for food. The writer further established that $90 \%$ of adolescents will consider eating food that is available before considering preferred foods. Similarly, Wardlaw and Smith (2009) described food availability as an important factor for food selection especially in the face of hunger. This means adolescents will consider food they have available in their choice of food.

In relation to Maslow's theory of human needs, physiological need involves what the human body requires at a point in time. Hence, adolescents will mostly consider eating food that is available than food they enjoy most. This also shows that they will accept and eat any food available without considering its health or nutritional composition.

According to Wardlaw and Smith (2009), adolescents' poor dietary practices are as a result of the availability of processed foods in shops and the open markets. In developed countries like United States adolescents' have been able to make significant changes in their eating habits due to the availability of wider food options.

\section{Conclusion}

The underlisted conclusions were drawn based on the findings of the study:

(1) Dietary practices of various types have been identified to be part of boarding students' lifestyle. Most students are not of the habit of skipping meals; however, among those who skip meals, breakfast is the meal that is often skipped.

(2) The students snack frequently on energy dense foods. Water and fruit intake among students are also inadequate and less encouraging. As part of the adolescent physiological and physical development they are likely to experience rampant hunger pangs that heighten their appetite for meals without thinking about their nutritional and health state.

(3) Water and fruit intake among students were also not encouraging.

(4) From the findings it was concluded that several factors influenced the dietary practice of the Boarding students of Winneba S.H.S. Hunger, Purchasing Power, Health conditions, Family, School Dining Menu, Availability of Food, Peer Influence and Religion are the eight (8) established factors which were identified that influenced the dietary practice of boarding students with percentages ranging between $95 \%$ a maximum and $60 \%$ minimum that contributed to various dietary practices of the students. Hunger and food availability are the main influencing factors of their dietary practices among several others identified.

\section{Recommendations}

This study is one of a kind undertaken within Winneba S.H.S serving as a preliminary attempt to evaluate the influence of dietary practice of selected boarding students on their academic performance. Several issues and factors erupted from the study which the researcher is of the view that, the under listed recommendations can help resolve.

(1) Based on the evidence that students skipped meals especially breakfast, the school authorities should ensure that all students are educated on the benefits of eating breakfast. Students should be made to understand that breakfast helps to supply one-third of the body's daily nutrients requirements. It helps to provide the essential organs like the brain with the needed energy and nourishment to help their proper functioning.

(2) As part of the orientation for fresh students, they must be educated on the importance of adopting a positive dietary practice in order to maintain a general wellbeing throughout their course period.

(3) In order to ensure that students do not skip their meals especially breakfast, attendance to dining hall must be made compulsory for all boarding students. If this is done, even students who do not intend to eat from the dining hall may be enticed by the appetite and zeal of those who have decided to eat. Teachers on duty, dining hall masters and mistresses must be strict on ensuring that students are present at the dining hall so that the students will have little or no time to queue at the school canteen. 
(4) The students should be educated on the relevance of consuming what is prepared for them in the school's dining hall. This should be done with collaborative efforts of the school management board, administration, members of staff, P.T.A., the entire prefectural body and most especially the Home Economics teachers.

(5) Based on the finding that students seldom ate fruits, the school's dining hall must serve students with fruits at least once daily. Students can be served with oranges which are relatively cheaper compared with other fruits yet are rich sources of vitamin $\mathrm{C}$ and fibre and is excellent in strengthening the immune system and maintaining free bowel movement.

(6) Professionals like the Home Economics teachers, dieticians and nutritionists could be regularly invited to the school to organize seminars and symposia for students in effort to guide students on how to live and adopt positive dietary practices. It is believed that, if adolescents are educated about healthy eating habits and increase their exposure to healthy foods, they can cultivate healthy lifestyle and even extend it to adulthood.

(7) As regards the role of parent, they are encouraged to try to set good examples for healthy eating. This may include parents preparing healthy family meals at home, limiting unhealthy snack consumption, and reducing eating out to either once a week or less. When this is done, parents' presence would not even be necessary to encourage healthy eating among their adolescent children. Another strategy will be to keep a regular supply of nutritious foods and fresh fruits in the home especially at the kitchen as this will impress upon adolescents the importance of healthy eating while limiting poor choices.

\section{References}

Adair, L. S. \& Popkin, B. M. (2005). Are child eating patterns being transformed globally? Obesity research, 13(7), 1281-1299

Alhassan, M. A. (2006). The scientific basis of the art of research. New York. Teachers College Press.

Amoakoh-Kwakye, F. Y. (2010). Food and food-related practices of cultural groups in Southern Ghana. Accra, Ghana: Ghana University Press.

Anderson A. S., McIntyre, S. \& West, P. (1994). Dietary patterns among adolescents in the west of Scotland. British Journal Nutrition, 71, 111-122 Retrieved from https://www.ucl.ac.uk/hbrc/resources/resources.

Asare, E. \& Kwafoa, M. (2011). Understanding Management in Living. Accra, Ghana: Kwadwoan Publishing.

Awanta, E. K., \& Asiedu-Addo, S. K. (2008). Essential statistical techniques in research. Accra: Salt "N" Light Publishers.

Barasi, E. (1997). Human nutrition: A health perspective. New York: Oxford University Press, Inc.

Befort, C., Kaur, H., Nollen, N., Sullivan, D. K., Nazir, N., Choi, W. S., Hornberger, L. \& Ahluwalia, J. J. (2006). Fruit, vegetable, and fat intake among non-Hispanic black and non-Hispanic white adolescents: Associations with home availability and food consumption settings. Journal of the American Dietetic Association, 106(3), 367-373.

Bediako, T. (2011). Food and nutrition for senior high schools in West Africa (5th ed.). Kumasi, Ghana: Esswin Publishing Ltd.

Bellisle, F. (2006). The factors that influence our food choices: retrieved from http//www.eufic.org/eg

Briggs, M., Mueller, C. G. \& Fleischhacker, S. (2010). Position of the American dietetic association, school nutrition association, and society for nutrition education: Comprehensive school nutrition services. Journal of the American Dietetic Association, 110, 1738-1749.

Brown, E. B. (2012). Nutrition through the life cycle. Australia: Thomson-Wardworth.

Dolar V. (2009). Who is eating away from home? Analysis using NHANES data 1971-2006. Minnesota: University of Minnessota. 
Dwyer, T., Blizzard, L. \& Dean, K. (2001). Physical activity and performance in children. Nutrition Reviews, 54 (2), $27-31$.

Eshun, P., \& Effrim, P. K. (2007), Basics in measurement, evaluation and statistics in education. Winneba: University of Education, Winneba, Ghana.

Fraenkel, J. R. \& Wallen, E. N. (2000). How to design and evaluate research in education (5th Ed.). New York, USA: Mcgraw Hill Companies.

Frongillo, E. A., Jyoti, D. F. \& Jones, S. J. (2006). Food stamp programme participation is associated with better academic learning among school children. The Journal of Nutrition, 136, 1077-1080.

Maslow, A. (1943). A theory of human motivation. Psychological Review, 50, 370-396

Mensah, S. (2006). Eating habits of senior high school students: a study of selected senior high schools in Cape Coast Metropolis. Unpublished Master's dissertation. University of Cape Coast.

Moody, H. R. (2010). Ageing Concepts and Controversies ( $6^{\text {th }}$ Ed) Pine Forge Press, SAGE Publications Company, London, United Kingdom.

Phillips, J. A. (2009). Educational research methodology. Selangor: Open University Malaysia

Poulain (2002). Health behavior and health education of adolescents. (2nd Ed.) San Francisco: Jossey-Bass,

Tull , A (1996). Food and nutrition. Oxford: Oxford University Press.

Vygotsky, L. S. (1978). Mind in society. Cambridge: Harvard University Press.

Wardlaw, G. M. \& Smith, A. M. (2009). Contemporary nutrition (8th Ed.). New York, USA: McGraw-Hill Companies Inc.

World Health Organization (1998). Obesity: Preventing and managing the global epidemic. Geneva: World Health Organization.

World Health Organization (2000). The management of nutrition in major emergencies. ( $2^{\text {nd }}$ ed.). Geneva: World Health Organization.

World Health Organization (2003). Diet, nutrition, and the prevention of chronic diseases: Report of a joint WHO/FAO expert consultation. Geneva, Switzerland: World Health Organization.

World Health Organization (2006). WHO Anthro for personal computers version 2. Retrieved on February 9, 2016 from https://www.who.int/childgrowth/software/. Date of access: 07 Jan 2009.

World Health Organization (2020). Adolescent health in South-East Asia Region. Retrieved from http://www.who.int/southeastasia/health-topic/adolescent-health 